\title{
Lower limb enthesopathy in patients with psoriasis without clinical signs of arthropathy: a hospital- based case-control study
}

\author{
P Gisondi, ${ }^{1}$ I Tinazzi, ${ }^{2}$ G El-Dalati, ${ }^{3}$ M Gallo, ${ }^{3}$ D Biasi, ${ }^{2}$ L M Barbara, ${ }^{2}$ G Girolomoni
}

${ }^{1}$ Department of Biomedical and Surgical Sciences, Section of Dermatology and Venereology, University of Verona, Verona, Italy; ${ }^{2}$ Department of Experimental and Clinical Medicine, Section of Rheumatology, University of Verona, Verona, Italy;

${ }^{3}$ Department of Biomedical and Morphological Sciences, Section of Radiology, University of Verona, Verona, Italy

Correspondence to: Paolo Gisondi, Department of Biomedical and Surgical Science, Section of Dermatology and Venereology, University of Verona, Piazzale A. Stefani 1, I37126 Verona, Italy; paolo. gisondi@univr.it

Accepted 8 August 2007 Published Online First 24 August 2007

\section{ABSTRACT}

Background: Psoriasis is associated with a form of spondyloarthropathy in 10-30\% of cases. A major feature of psoriatic arthritis is enthesitis. In some patients with psoriasis the presence of enthesitis could be underdiagnosed.

Objective: To investigate the presence of lower limbs entheseal abnormalities in patients with chronic plaque psoriasis without signs and symptoms of psoriatic arthritis.

Methods: Thirty patients with psoriasis and 30 controls underwent ultrasonographic evaluation of Achilles, quadriceps, patellar entheses and plantar aponeurosis.

Ultrasonographic findings were scored according to the Glasgow Ultrasound Enthesitis Scoring System (GUESS).

Results: Mean GUESS score was significantly higher in patients with psoriasis as compared with controls: 7.9 (0.6) vs $2.9(0.3) ; p<0.0001$. In particular, the thickness of all tendons examined was significant higher in cases than in controls $(p<0.0001)$, as well as the number of enthesophytes in all sites examined. In both cases and controls, the GUESS score was directly correlated with age $(r=0.22 ; p=0.008)$, body mass index $(r=0.23$, $p=0.0067)$ and waist circumference $(r=0.17$; $p=0.02$ ). In contrast, the GUESS score was not correlated with the duration and severity of psoriasis according to the Psoriasis Area and Severity Index $(r=0.03 ; p=0.8)$ and body surface area involvement $(r=0.07 ; p=0.6)$.

Conclusions: Entheseal abnormalities can be documented by ultrasonography in clinically asymptomatic patients with psoriasis. These findings could be related to a subclinical entheseal psoriatic inflammation. We suggest close follow-up of patients with psoriasis with entheseal abnormalities for early diagnosis of psoriatic arthritis.

Psoriasis is a chronic inflammatory skin disease that can be associated to a form of spondyloarthropathy, known as psoriatic arthritis (PsA). In most patients psoriasis precedes the onset of PsA, although there is no relationship between the severity of skin disease and the occurrence of PsA. Prevalence of PsA in patients with psoriasis varies from 7.6 to $36 \%$ according to different populations studied. ${ }^{1-7}$ Moreover, $3-8 \%$ of patients with psoriasis had articular symptoms, including arthralgia, morning stiffness and paraesthesia in the absence of sufficient criteria for the diagnosis of PsA. ${ }^{89}$ Entheses are the initial site of joint inflammation in spondyloarthropathy and enthesitis most commonly localises in the lower limbs. ${ }^{11}{ }^{11}$ In some patients with psoriasis the presence of enthesitis could be missed during clinical evaluation.
Musculoskeletal ultrasonography is widely available and inexpensive, and readily demonstrates superficial tissue inflammation such as fluid collections, soft tissue lesions, entheseal and tendon abnormalities, as well as bone surface lesions with a sensitivity comparable with magnetic resonance imaging. ${ }^{12}$ The aim of the present study was to investigate the presence of entheseal abnormalities by means of ultrasonography in patients with psoriasis without clinical signs of PsA, compared with patients with skin disease other than psoriasis. The results indicate that entheseal abnormalities can be documented in clinically asymptomatic patients with psoriasis. These patients may need a closer follow-up for the early detection of PsA.

\section{METHODS}

\section{Study population}

This was a hospital-based case-control study involving a series of 30 patients with chronic plaque psoriasis and 30 age- and sex-matched controls consecutively admitted to the outpatients clinic. The source population for cases and controls was the same, including patients referred to the University Hospital of Verona. Inclusion criteria for cases were: age $>18$ years; diagnosis of chronic plaque psoriasis lasting $>1$ year; absence of any clinical signs and symptoms of articular involvement (including axial and peripheral involvement); absence of clinical signs and symptoms of enthesopathy (including Achilles, quadriceps, patellar and plantar aponeurosis enthesitis); absence of radiological signs of spinal hyperostosis and absence of any systemic treatment for psoriasis in the previous 3 months prior to clinical and ultrasound evaluation. In particular, no patients had ever received retinoids (acitretin or etretinate) for psoriasis. Controls were enrolled among patients referred to the same hospital for dermatological diseases other than psoriasis, including skin carcinomas $(55 \%)$, atopic or contact eczema $(32.5 \%)$ or chronic urticaria (12.5\%). Articular examination was performed according to standard procedures. Severity of psoriasis was scored according to the Psoriasis Area and Severity Index (PASI) and body surface area (BSA) measurements. ${ }^{13} \mathrm{~A}$ target nail was selected for each case patient and psoriatic nail involvement was graded according to Nail Psoriasis Severity Index (NAPSI), that is a numeric (ranging from 0 to 32), reproducible, objective, simple tool for the evaluation of nail psoriasis. ${ }^{14}$ Registered socio-demographic characteristics of the study population included body mass index (BMI), waist 
circumference, co-morbidities and age of onset of psoriasis. Venous samples were taken at the enrolment visit after the subjects had fasted overnight (at least $8 \mathrm{~h}$ ). Serum cholesterol, triglycerides and uric acid were measured with enzymatic procedures. Plasma glucose was measured using a glucose oxidase method. This study was approved by the Ethical Committee.

\section{Ultrasonography}

Real-time ultrasonography was performed by both an experienced radiologist and a rheumatologist, using an ATL HDI 3000 machine with a linear $10-15 \mathrm{MHz}$ probe. The rheumatologist received a certified university training in musculoskeletal ultrasonography and she was very familiar with the routine use of ultrasound for the detection of early rheumatoid arthritis. Both the radiologist and the rheumatologist were blinded, that is, they were not aware if patients were affected by psoriasis or other skin diseases, and the ultrasonographic examination was performed in a darkened room. Examination of the superior pole of the patella (quadriceps tendon insertion), the inferior pole of the patella (patellar ligament origin) and the patellar ligament insertion at the tibial tuberosity was performed with the patient in the supine position with the knee flexed at $30^{\circ}$. The Achilles tendon and the plantar aponeurosis were examined with the patient lining prone with the feet hanging over the edge of the examination table at $90^{\circ}$ of flexion. Ultrasonographic assessment of structure, thickness and the presence or absence of bony erosions, enthesophytes and bursitis was recorded at each site. Ultrasonographic findings were scored according to Glasgow Ultrasound Enthesitis Scoring System (GUESS), which was validated by Balint et $a l^{15}$ in order to compare ultrasonography with clinical examination in the detection of entheseal abnormalities of lower limbs in patients with spondyloarthropathy. GUESS is an easily reproducible standardised measure of lower limb entheseal ultrasonographic abnormalities, ranging from 0 to $36 .{ }^{15}$ It incorporates the assessment of tendon thickness, and the presence of bone erosions, enthesophytes and bursitis recorded at the Achilles, quadriceps and patellar tendons and plantar aponeurosis. Clinically, enthesitis is suspected and afterwards better confirmed by power Doppler ultrasonography and/or magnetic resonance. ${ }^{16}$ Validation ultimately comes down to histological confirmation, ${ }^{17}$ but this is very rarely performed in clinical practice.

\section{Plain radiography}

A SIEMENS OPTI 150/30/50 HC-100, model 4803388 instrument was used (Malvern, PA, USA). A plain radiography of spinal, knee and foot was performed in both cases and controls, in order to detect the presence of hyperostosis, calcifications, bone erosions and bone apposition. Examination of the superior pole of the patella (quadriceps tendon insertion), the inferior pole of the patella (patellar ligament origin), and the patellar ligament insertion at the tibial tuberosity was performed with the patient in the supine position with the knee flexed at $30^{\circ}$. The Achilles tendon and the plantar aponeurosis were examined with the patient lining supine with the feet at $90^{\circ}$ of flexion. Radiographies were useful to confirm the presence of enthesophytes detected by ultrasound and to exclude spinal hyperostosis suggestive of diffuse idiopathic skeletal hyperostosis. ${ }^{18}$ The number of calcifications evident by plain radiography were measured and GUESS was re-scored (GUESS modified) without including these in the computation. The main advantage of not considering radiological calcifications is to take into account only enthesophytes due to inflammatory processes.

\section{Statistical analysis}

Analysis was made using the STATA (version 6.0 Stata-Corp LP, College Station, TX, USA) and Graphpad (version 4.0 GraphPad Software, El Camino Real, San Diego, CA, USA) software packages. Standard descriptive statistics such as mean and standard deviation were computed. Associations between the presence of psoriasis and various covariates were tested by using the Fisher exact test for categorical variables and t test for continuous variables. Linear correlation between covariates were analysed according to Spearman test for non-parametric variables and Pearson for parametric variables. The intraobserver agreement was calculated using a $\kappa$ test. Analysis of covariance (ANCOVA) was also performed. All $p$ values are two-sided and $p<0.05$ was considered statistically significant.

\section{RESULTS}

Descriptive characteristics of study population are reported in table 1. Cases had mild to severe chronic plaque psoriasis with a PASI score ranging from 1.6 to 30.2 with a median 7.54 (95\% CI 7.4 to 9.6 ); 17 patients (56.6\%) had a PASI score $<10$, whereas 13 had a PASI score $\geqslant 10$. BSA involvement ranged from 1 to $45 \%$, with a median of 10.6 (95\% CI 14.9 to 19.1$)$; 18 patients (60\%) had a BSA $<10 \%$, whereas 12 had a BSA $\geqslant 10 \%$. Mean NAPSI score was 10.3 (95\% CI 7.9 to 15.1). Controls included 15 females and 15 males with a mean age of $56.7 \pm 13.9$ (age ranged from 29 to 78 years). There were no significant differences in sex distribution, mean age, BMI, waist circumference, glycaemia, cholesterolaemia, triglyceridaemia and uric acid plasma levels between cases and controls (table 1).

GUESS score and main sonographic findings are reported in table 2. Mean GUESS score was significantly higher in patients with psoriasis as compared with controls: 7.9 (0.6) vs 2.9 (0.3), $\mathrm{p}<0.0001$ (fig 1a). Moreover, also rescoring GUESS without including calcifications evident with plain radiography (ie, GUESS modified) the difference between cases and controls was still statistically significant: 5.0 (2.1) vs 2.8 (0.3), p $<0.01$ (fig 1b). In particular, the mean thickness of all tendons examined was significantly higher in cases than in controls $(p<0.0001)$ as well as the mean number of enthesophytes in all sites examined (fig 2a,b). We found that thickening was preferentially (almost $70 \%$ of cases) associated with loss of fibrillar echogenicity than to hypoechoic change (fig 2b,c). In both cases and controls GUESS score was directly correlated with age $(r=0.22 ; p=0.008)$ (fig $1 c)$, BMI $(r=0.23 ; p=0.0067)$ (fig 1d), and waist circumference $(r=0.17 ; p=0.02)$. Although there were no differences in BMI between cases and controls, we performed a covariate analysis to adjust the statistical

Table 1 Description of the study population

\begin{tabular}{|c|c|c|c|}
\hline & Cases & Controls & p value \\
\hline $\mathrm{N}$ & 30 & 30 & 1 \\
\hline Sex distribution (M:F) & 18:12 & $15: 15$ & 0.8 \\
\hline Age (years), mean (SD) & $55.8(13.2)$ & \multicolumn{2}{|c|}{$56.7(13.70 .7$} \\
\hline $\mathrm{BMI}$, mean (SD) & $28.5(4.2)$ & \multicolumn{2}{|c|}{$28.4(2.4) 0.8$} \\
\hline Waist circumference $(\mathrm{cm})$, mean $(\mathrm{SD})$ & $104.5(12.8$ & \multicolumn{2}{|c|}{ ) $102.4(9.1) 0.1$} \\
\hline Glycaemia $(\mathrm{mg} / \mathrm{dl})$, mean (SD) & $116(15.6)$ & $105(16.8)$ & 0.08 \\
\hline Cholesterolaemia (mg/dl), mean (SD) & $245(10.2)$ & $230(12.8)$ & 0.9 \\
\hline Triglyceridaemia (mg/dl), mean (SD) & $208(12.2)$ & $201(14.8)$ & 0.9 \\
\hline Uric acid $(\mathrm{mg} / \mathrm{dl})$, mean $(\mathrm{SD})$ & $6.1(2.2)$ & \multicolumn{2}{|c|}{$5.6(2.3) 0.7$} \\
\hline
\end{tabular}


evaluation for BMI and body weight. According to the adjustment in BMI, the difference in GUESS score was still statistically significant: $7.5(0.5)$ vs $2.8(0.2), p<0.0001$. In contrast, the GUESS score was not correlated with either the duration or the severity of psoriasis according to the PASI index $(r=0.03 ; p=0.8)$, BSA involvement $(r=0.07 ; p=0.6)$ as well as to severity of nail psoriasis $(r=0.05 ; p=0.7)$. We did not observe bone erosions neither in cases nor in controls, whereas we found six patients with psoriasis with retrocalcaneal bursitis, but no bursitis in controls $(p=0.0001)$ (fig $2 c)$. The intraobserver $\kappa$ value for analysis of all sites was 0.9 . The $\kappa$ values for the analysis of separate lesions were as follows: tendon thickness $\kappa=0.91$; bone erosions and bursitis $\kappa=0.98$; enthesophytes $\kappa=0.88$.

\section{DISCUSSION}

This study found that entheseal abnormalities can be documented by ultrasonography in clinically asymptomatic patients with psoriasis. In particular, thickness of lower limb entheses examined and number of enthesophytes were significant higher in patients with psoriasis than in controls. Bone erosions were not observed neither in cases nor in controls, whereas six patients with psoriasis had retrocalcaneal bursitis. Similar findings were rarely reported by other authors. In particular, De Filippis et $a l^{19}$ found that entheseal abnormalities not detected at clinical examination were present in six of 24 (25\%) patients with psoriasis who underwent ultrasonography. Similarly, Ozcakar et $a l^{20}$ found that the mean thickness of the Achilles' tendon was significantly higher in patients with psoriasis (without clinical sign of enthesitis) than in healthy volunteers. Achilles sonographic abnormalities in 35 of 59 patients with psoriasis (59.2\%) were also reported by De Simone et al. ${ }^{21}$ However, in this study, 15 of 58 patients with PsA were included. Finally, Galluzzo et $a l^{22}$ found a high prevalence of involvement of the tendons and entheses of the ankle in clinically asymptomatic PsA patients, suggesting that clinical evaluation underestimates these manifestations. Our data confirm that entheseal abnormalities are common in patients with psoriasis without clinical sign of articular involvement and we suggest that these findings could be related to a entheseal psoriatic inflammation, which is not clinically apparent. We measured the entheseal abnormalities according to the GUESS score and the modified GUESS score, which takes into account only enthesophytes due to inflammatory processes excluding those due to degenerative processes. Moreover, we found a small but significant correlation between GUESS score and BMI, waist circumference, and age in both cases and controls, whereas there was no correlation between GUESS score and duration and severity of psoriasis. Apart from inflammatory tendinitis other disorders that are known to increase tendon thickness include trauma, diabetes, familiar hypercholesterolaemia and gout tophi, all conditions that were excluded in our patients. ${ }^{23}{ }^{24}$ Another relevant factor that may affect tendon thickness is the BMI. It has been reported that there is an association between the thickness of the Achilles tendon and BMI either in healthy individuals but also in female patients with diabetes. ${ }^{25} 26$ We did not observe any statistically significant difference between patients with psoriasis and controls in terms of BMI as well as mean glycaemia, cholesterol, triglycerides and uric acid levels. Even if we adjusted the GUESS score according to all of the above-mentioned confounding factors, the adjusted GUESS score value was still significantly higher in cases than in controls, which supported that the presence of enthesopathy in our patients is independent from the confounding. As far as iatrogenic causes of enthesopathy, retinoids are known to induce hyperostosis, most notably when they are used in high dosages and over long periods $;^{27}$ therefore, we included in the study only patients that never received retinoids. The role of ageing on tendon thickness is uncertain, although more recently it has been reported that Achilles tendon thickness was similar in young and middle-aged people. ${ }^{28}$ We suggest that psoriasis is an independent factor, which may favour either tendon thickness and enthesophyte production possibly due to subclinical entheseal psoriatic inflammation.
Figure 1 (A) Glasgow Ultrasound Enthesitis Scoring System (GUESS) scores of patients with psoriasis and controls (p). (B) GUESS modified score in patients with psoriasis and controls ( $p)$. (C) Linear correlation between GUESS score and age according to Pearson test $(r=0.22 ; p=0.008)$. (D) Linear correlation between GUESS score and BMI according to Pearson test $(r=0.23$; $p=0.0067$ ).
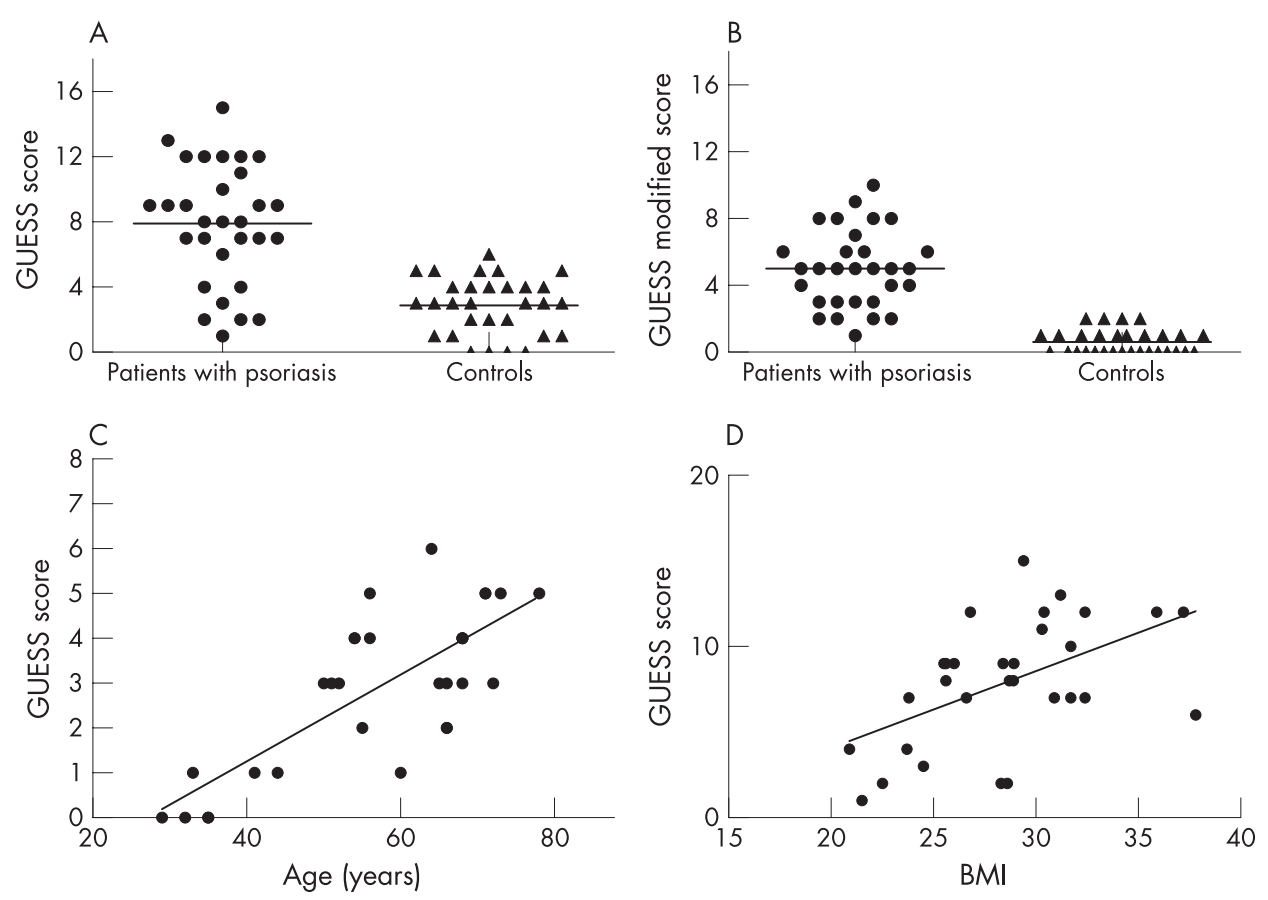

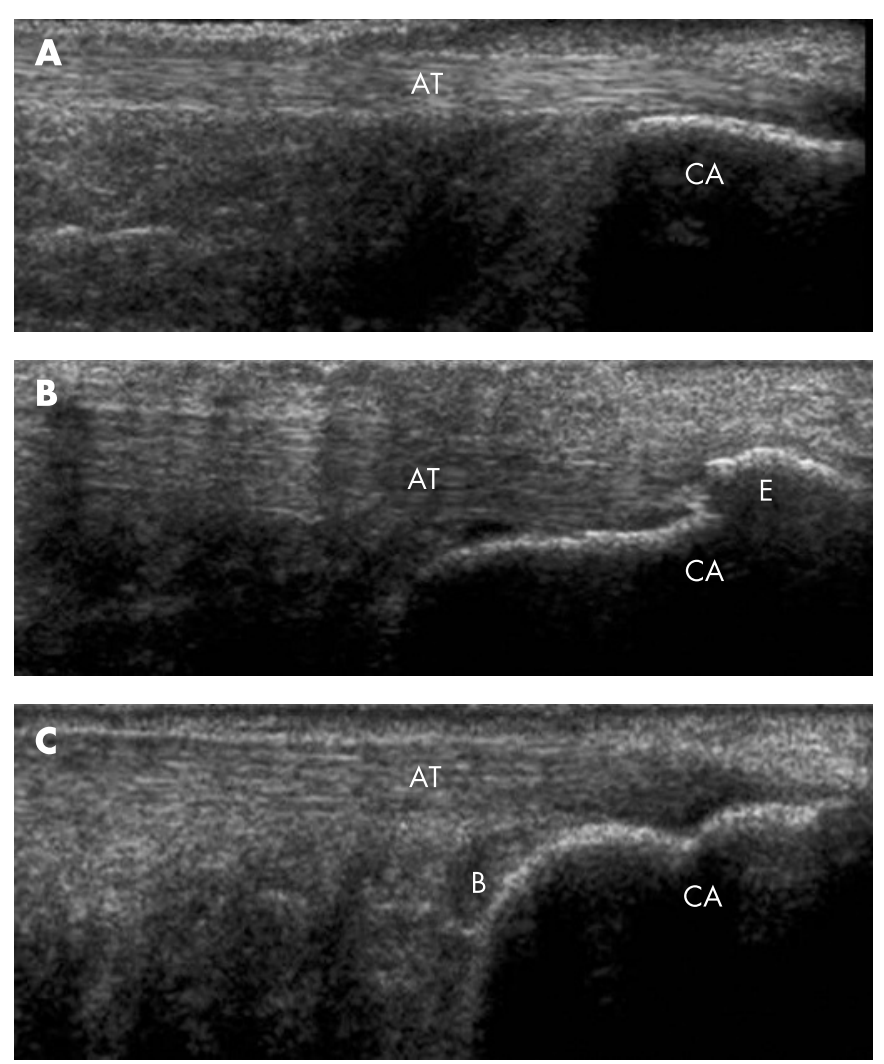

Figure 2 (A) Ultrasonographic image of normal Achilles tendon $(3.8 \mathrm{~mm})$ in a control subject. (B) Ultrasonographic image of a thickened Achilles tendon $(7.1 \mathrm{~mm})$ and enthesophyte in a psoriatic patient. (C) Ultrasonographic image of a thickened Achilles tendon $(6.8 \mathrm{~mm})$ associated to a retrocalcaneal bursa (diameter $6.9 \times 2.4 \mathrm{~mm}$ ) in a psoriatic patient. AT, Achilles tendon; $B$, retrocalcaneal bursa; $C A$, calcaneus; $\mathrm{E}$, enthesophyte.

Table 2 GUESS score in the study population

\begin{tabular}{|c|c|c|c|}
\hline & Cases & Controls & p value \\
\hline Quadriceps tendon thickness $>6.1 \mathrm{~mm} ; \mathrm{N}^{*}(\%) \dagger$ & $18(30)$ & $2(3.3)$ & 0.0001 \\
\hline Suprapatellar bursitis; N (\%) & $1(1.6)$ & 0 & 0.8 \\
\hline Superior pole of patella erosion; $\mathrm{N}(\%)$ & 0 & 0 & 1 \\
\hline Superior pole of patellar enthesophyte; N (\%) & $41(68.3)$ & $24(40)$ & 0.005 \\
\hline $\begin{array}{l}\text { Patellar ligament thickness }>4 \mathrm{~mm} \text { (inferior pole of } \\
\text { patella); N (\%) }\end{array}$ & f $22(36.6)$ & $14(23.3)$ & 0.02 \\
\hline Inferior pole of patella erosion; N (\%) & 0 & 0 & 1 \\
\hline Inferior pole of patella enthesophyte; $\mathrm{N}(\%)$ & $20(33.3)$ & $12(20)$ & 0.01 \\
\hline $\begin{array}{l}\text { Patellar ligament thickness }>4 \mathrm{~mm} \text { (insertion at } \\
\text { the tibial tuberosity); } \mathrm{N}(\%)\end{array}$ & $21(35)$ & $10(16.7)$ & 0.01 \\
\hline Infrapatellar bursitis; N (\%) & 0 & 0 & 1 \\
\hline Tibial tuberosity erosion; $\mathrm{N}(\%)$ & 0 & 0 & 1 \\
\hline Tibial tuberosity enthesophyte; N (\%) & $14(23.3)$ & $1(1.6)$ & 0.0001 \\
\hline Achilles tendon thickness $>5.29 \mathrm{~mm}$; N (\%) & $10(16.6)$ & $1(1.6)$ & 0.0001 \\
\hline Retrocalcaneal bursitis; N (\%) & $6(10)$ & 0 & 0.0001 \\
\hline Posterior pole of calcaneus erosion; $\mathrm{N}(\%)$ & 0 & 0 & 1 \\
\hline Posterior pole of calcaneus enthesophyte; N (\%) & $54(90)$ & $20(33.3)$ & 0.0001 \\
\hline Plantar aponeurosis thickness $>4.4 \mathrm{~mm} ; \mathrm{N}(\%)$ & $3(5)$ & 0 & 0.8 \\
\hline Inferior pole of calcaneus erosion; N (\%) & 0 & 0 & 1 \\
\hline Inferior pole of calcaneus enthesophyte; N (\%) & $23(38.3)$ & $22(36.6)$ & 0.8 \\
\hline
\end{tabular}

${ }^{*} \mathrm{~N}$ is the number of entheseal sites resulted abnormal according to the GUESS score. $\dagger(\%)$ is the prevalence entheseal sites abnormalities in the case and control population respectively.
The major limitation of our study is the small number of patients investigated and the absence of long-term follow-up, which may show whether some of the patients could later develop PsA. As enthesopathic changes have been suggested as being the unifying and early feature of PsA, these patients need a closer follow-up for the early detection of PsA. ${ }^{29} 30$ PsA can be associated with a progressive and irreversible damage of the entheses in a relatively short time. ${ }^{31}$ Therefore, we suggest the routine use of ultrasonography in the early diagnosis of patients with tendon enthesopathy, as these factors may have implications for therapy and the prevention of progression of PsA.

Competing interests: none

\section{REFERENCES}

1. Salvarani C, Lo Scocco G, Macchioni P, Cremonesi T, Rossi F, Mantovani W, et al. Prevalence of psoriatic arthritis in Italian psoriatic patients. J Rheumatol 1995:22:1499-503.

2. Scarpa R, Oriente P, Pucino A, Torella M, Vignone L, Riccio A, et al. Psoriatic arthritis in psoriatic patients. Br J Rheumatol 1984;23:246-50.

3. Biondi Oriente C, Scarpa R, Pucino A, Oriente P. Psoriasis and psoriatic arthritis Dermatological and rheumatological co-operative clinical report. Acta Derm Venereol 1989:146:69-71.

4. Alamanos Y, Papadopoulos NG, Voulgari PV, Siozos C, Psychos DN, Tympanidou M, et al. Epidemiology of psoriatic arthritis in northwest Greece, 1982-2001. J Rheumatol 2003:30:2641-4.

5. Shbeeb M, Uramoto KM, Gibson LE, O'Fallon WM, Gabriel SE. The epidemiology of psoriatic arthritis in Olmsted County, Minnesota, USA, 1982-1991. J Rheumatol 2000:27:1247-50.

6. Barisic-Drusko V, Dobric I, Pasic A, Paljan D, Jukic Z, Basta- Juzbasic A, et al Frequency of psoriatic arthritis in general population and among the psoriatics in department of dermatology. Acta Derm Venereol 1994:186:107-8.

7. Gisondi P, Girolomoni G, Sampogna F, Tabolli S, Abeni D. Prevalence of psoriatic arthritis and joint complaints in a large population of Italian patients hospitalised for psoriasis. Eur J Dermatol 2005;15:279-83.

8. Zanolli MD, Wikle JS. Joint complaints in psoriasis patients. Int J Dermatol 1992:31:488-91.

9. Stern RS. The epidemiology of joint complaints in patients with psoriasis. J Rheumatol 1985;12:315-20.

10. McGonagle D, Gibbon W, Emery P. Classification of inflammatory arthritis by enthesitis. Lancet 1998;352:1137-40.

11. McGonagle D, Gibbon W, O'Connor P, Green M, Pease C, Emery P. Characteristic magnetic resonance imaging entheseal changes of knee synovitis in spondylarthropathy. Arthritis Rheum 1998;41:694-700.

12. Kamel M, Eid H, Mansour R. Ultrasound detection of knee patellar enthesitis: a comparison with magnetic resonance imaging. Ann Rheum Dis 2004;63:213-4.

13. Langley RG, Ellis CN. Evaluating psoriasis with Psoriasis Area and Severity Index, Psoriasis Global Assessment, and Lattice System Physician's Global Assessment. J Am Acad Dermatol 2004;51:563-9.

14. Cassell SE, Bieber JD, Rich P, Tutuncu ZN, Lee SJ, Kalunian KC, Wu CW, Kavanaugh A. The modified Nail Psoriasis Severity Index: validation of an instrument to assess psoriatic nail involvement in patients with psoriatic arthritis. J Rheumatol 2007:34:123-9.

15. Balint PV, Kane D, Wilson H, Mclnnes IB, Sturrock RD. Ultrasonography of entheseal insertions in the lower limb in spondyloarthropathy. Ann Rheum Dis 2002;61:905-10.

16. Eshed I, Bollow M, McGonagle DG, Tan AL, Althoff CE, Asbach P, et al. Magnetic resonance imaging of enthesitis of the appendicular skeleton in spondyloarthritis. Ann Rheum Dis. Published on line first: 2007 May 25. doi: ard.2007.070243v1.

17. McGonagle D, Marzo-Ortega H, O'Connor P, Gibbon W, Hawkey P, Henshaw K, et al. Histological assessment of the early enthesitis lesion in spondyloarthropathy. Ann Rheum Dis 2002;61:534-7

18. Cammisa M, De Serio A, Guglielmi G. Diffuse idiopathic skeletal hyperostosis Eur J Radiol 1998;27:7-11.

19. De Filippis LG, Caliri A, Lo Gullo R, Bartolone S, Miceli G, Cannavo SP, et al. Ultrasonography in the early diagnosis of psoriasis-associated enthesopathy. Int J Tissue React 2005;27:159-62.

20. Ozcakar L, Cetin A Inanici F, Kaymak B, Gurer CK, Kolemen F. Ultrasonographical evaluation of the Achilles' tendon in psoriasis patients. Int J Dermatol 2005;44:930-2

21. De Simone C, Guerriero C, Giampetruzzi AR, Costantini M, Di Gregorio F, Amerio P. Achilles tendinitis in psoriasis: clinical and sonographic findings. J Am Acad Dermatol 2003;49:217-22.

22. Galluzzo E, Lischi DM, Taglione E, Lombardini F, Pasero G, Perri G, et al. Sonographic analysis of the ankle in patients with psoriatic arthritis. Scand J Rheumatol 2000;29:52-5.

23. Descamps $\mathbf{O S}$, Leysen $\mathrm{X}$, Van Leuven F, Heller FR. The use of Achilles tendon ultrasonography for the diagnosis of familial hypercholesterolemia. Atherosclerosis 2001;157:514-18.

24. Akturk M, Ozdemir A, Maral I, Yetkin I, Arslan M. Evaluation of achilles tendon thickening in type 2 diabetes mellitus. Exp Clin Endocrinol Diabetes 2007;115:92-6. 
25. Schweitzer ME, Karasick D. MR imaging of disorders of the Achilles tendon Am J Roentgenol 2000;175:613-25.

26. Civeira F, Castillo JJ, Calvo C, Ferrando J, de Pedro C Martinez-Rodes $\mathrm{P}$, et al. Achilles tendon size by high resolution sonography in healthy population. Relationship with lipid levels. Med Clin (Barc) 1998:111:41-4.

27. Vincent V, Zabraniecki L, Loustau O, Godfrin B, Latour FB, Railhac JJ, et al. Acitretininduced enthesitis in a patients with psoriatic arthritis. Joint Bone Spine 2005; 72:326-9.
28. Du YC, Chen YF, Lin CJ, Lin YC, Chen T. The application of quantitative ultrasound on study of aging effects of Achilles tendons. Conf Proc IEEE Eng Med Biol Soc 2005;6:6344-7.

29. McGonagle D. Imaging the joint and enthesis: insights into pathogenesis of psoriatic arthritis. Ann Rheum Dis 2005;64(Suppl 2):ii58-60.

30. Gladman DD, Antoni C, Mease P, Clegg D0, Nash P. Psoriatic arthritis: epidemiology, clinical features, course, and outcome. Ann Rheum Dis 2005;64(Suppl 2):ii14-7.

31. Kane D, Pathare S. Early psoriatic arthritis. Rheum Dis Clin North Am 2005:31:641-57.

\section{BMJ Clinical Evidence-Call for contributors}

BMJ Clinical Evidence is a continuously updated evidence-based journal available worldwide on the internet which publishes commissioned systematic reviews. BMJ Clinical Evidence needs to recruit new contributors. Contributors are healthcare professionals or epidemiologists with experience in evidence-based medicine, with the ability to write in a concise and structured way and relevant clinical expertise.

Areas for which we are currently seeking contributors:

- Secondary prevention of ischaemic cardiac events

- Acute myocardial infarction

- MRSA (treatment)

- Bacterial conjunctivitis

However, we are always looking for contributors, so do not let this list discourage you.

Being a contributor involves:

- Selecting from a validated, screened search (performed by in-house Information Specialists) valid studies for inclusion.

- Documenting your decisions about which studies to include on an inclusion and exclusion form, which we will publish.

- Writing the text to a highly structured template (about 1500-3000 words), using evidence from the final studies chosen, within 8-10 weeks of receiving the literature search.

- Working with BMJ Clinical Evidence editors to ensure that the final text meets quality and style standards.

- Updating the text every 12 months using any new, sound evidence that becomes available. The $B M J$ Clinical Evidence in-house team will conduct the searches for contributors; your task is to filter out high quality studies and incorporate them into the existing text.

- To expand the review to include a new question about once every 12 months.

In return, contributors will see their work published in a highly-rewarded peer-reviewed international medical journal. They also receive a small honorarium for their efforts.

If you would like to become a contributor for BMJ Clinical Evidence or require more information about what this involves please send your contact details and a copy of your CV, clearly stating the clinical area you are interested in, to CECommissioning@bmjgroup.com.

\section{Call for peer reviewers}

BMJ Clinical Evidence also needs to recruit new peer reviewers specifically with an interest in the clinical areas stated above, and also others related to general practice. Peer reviewers are healthcare professionals or epidemiologists with experience in evidence-based medicine. As a peer reviewer you would be asked for your views on the clinical relevance, validity and accessibility of specific reviews within the journal, and their usefulness to the intended audience (international generalists and healthcare professionals, possibly with limited statistical knowledge).

Reviews are usually $1500-3000$ words in length and we would ask you to review between 2-5 systematic reviews per year. The peer review process takes place throughout the year, and our turnaround time for each review is 10-14 days. In return peer reviewers receive free access to BMJ Clinical Evidence for 3 months for each review.

If you are interested in becoming a peer reviewer for BMJ Clinical Evidence, please complete the peer review questionnaire at www.clinicalevidence.com/ceweb/contribute/peerreviewer.jsp 